\title{
Monitoring avian productivity and survivorship in the oil sands region of Northeastern Alberta
}

\author{
K.R. Foster Owl Moon Environmental Inc., Canada \\ C.M. Godwin Owl Moon Environmental Inc., Canada \\ P. Pyle Institute for Bird Populations, USA
}

\begin{abstract}
Avian demographics provide an indication of habitat quality and complexity, due to the habitat requirements of the individual species among landbird taxa. The MAPS protocol (Monitoring Avian Productivity and Survivorship) was applied in a 2011 pilot program in the boreal forest in the oil sands region to determine the applicability of the protocol in supporting evaluations of reclaimed habitats and to provide data supportive of population trend analyses. Six MAPS stations were established: three (BPND, MUSR, VWET) in natural undisturbed areas, two (GWAY, BISN) in reclaimed areas, and one (BCDS) in a seminatural, reservoir shoreline area. The abundance of birds processed in 2011 was high (1,937 captures and 1,605 new bandings). Capture rate was highest at the natural habitat MUSR station (885 per 600 net-hr) and lowest at the reclaimed GWAY station (140). Capture rate at the reclaimed BISN station (730) was similar to that at the natural stations. Mean apparent productivity (across all species) in natural habitat stations was 0.91 (SE 0.24), that at BISN was higher (1.28), and that at GWAY was lower (0.24). Diversity of captured birds ranged from 19 (GWAY) to 37 (BISN) species; however, the number of species observed and exhibiting breeding behaviours at these two reclaimed stations were similar to those at the natural and semi-natural stations. Up to nine species and four breeding species at each station are listed as sensitive in Alberta or Canada. Improvements in reclamation practices at BISN relative to those applied at GWAY may explain some of the differences in bird abundance, productivity and diversity. The MAPS protocol can be effectively applied in the region, will provide data and information on the quality of reconstructed habitats in reclaimed areas, and will contribute data for use in estimating population vital rates.
\end{abstract}

\section{Introduction}

Monitoring Avian Productivity and Survivorship (MAPS) is a formal, scientific, and statistically-robust program seeking to understand the population ecology of migratory and resident landbirds, to identify the demographic components of species' that are susceptible to anthropogenic disturbance, and to investigate the effects of disturbance on populations. This is conducted by the application of a standard methodology at over 1,000 monitoring stations in North America, where reproductive success and survival are quantified. The Institute for Bird Populations (IBP) provides overall program coordination.

MAPS provides information on vital rates (population sizes and trends, recruitment, productivity, and survivorship rates, and lambda, the projected rate of population change) that are critically needed to identify demographic causes for population declines of many North American landbirds (DeSante et al., $1999,2001)$. Vital-rate data have proven essential in efforts to identify management strategies attempting to reverse such population declines (DeSante, 1995; DeSante and Rosenberg, 1998). Vulnerabilities differ among species, with some species being sensitive to impacts on the summer breeding and rearing grounds, others being impacted on the winter grounds, and some being affected during migration. Thus, if productivity of a neo-tropical migratory landbird species is adequate but survival is low, managers on higher-latitude breeding grounds, including in Canadian boreal forest, may not be able to address population declines, whereas species with low productivity but adequate survival should be more responsive to boreal forest habitat management actions. 
The boreal forest is the breeding and rearing grounds for a large number of migratory and resident bird species (Savage, 2004; Blancher and Wells, 2005; Crewe et al., 2008; Wells, 2011), some of which are classified as rare, threatened or sensitive (Alberta Sustainable Resource Development, 2010; Committee on the Status of Endangered Wildlife in Canada, 2011; Government of Canada, 2009). However, few data have been collected that can establish a cause-and-effect relationship between industrial development, including reclamation programs, and bird population trends (Wells, 2011). For example, only eight of 975 MAPS stations operated between 1989 and 2006 occurred in the MAPS Boreal and Arctic Canada Region (Figure 1), and less than $0.6 \%$ of MAPS capture records came from this region. Increased numbers of MAPS stations in the boreal forest will increase the ability to derive population trends for many landbird species not otherwise monitored for vital rates (DeSante and Saracco, 2009; Saracco et al., 2009).

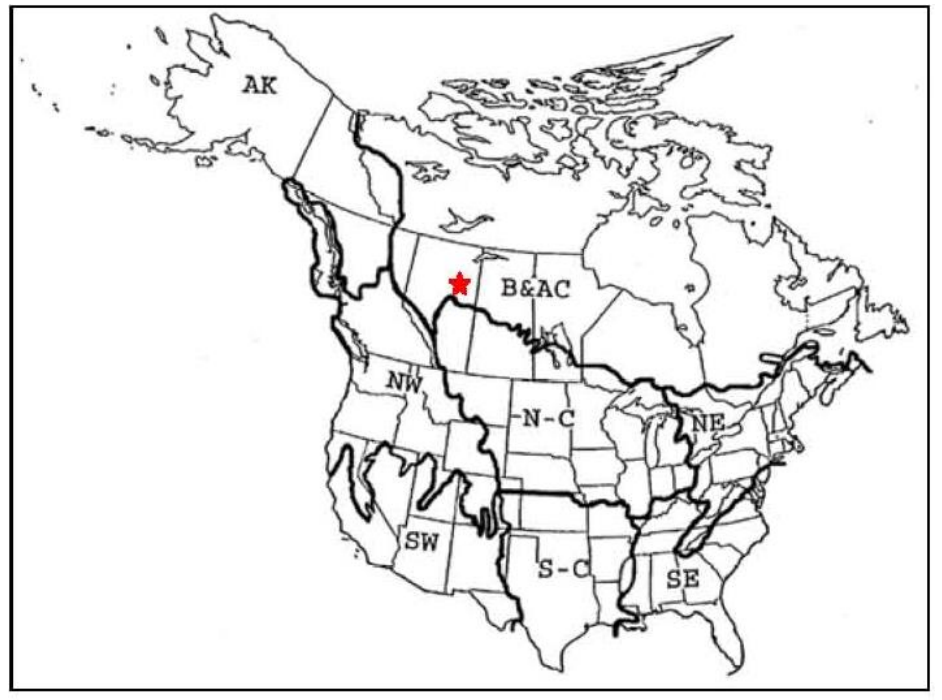

Figure 1 MAPS banding regions. Oil sands MAPS area indicated by red star. Eight MAPS regions include the Boreal \& Arctic Canada (B\&AC) region in which the oil sands MAPS stations are located

In 2011, six MAPS stations were established in the boreal forest in the oil sands region. Program objectives were to (1) advance the understanding of avian population dynamics and diversity in reclaimed habitats and in habitats subject to disturbances associated with industrial activities, and (2) acquire data for use in estimating population vital rates for bird species nesting in the boreal forest. Specific uses and applications of the MAPS program, and the data acquired, include reclamation success monitoring, application for reclamation certification, biodiversity monitoring and assessment, evaluation of potential industrial and non-industrial (e.g. urban development and activities) human effects, and evaluation of broad environmental change and natural environmental processes. Data from reclaimed and disturbed areas will be compared with data from unaltered boreal forests to achieve these goals.

\section{$2 \quad$ Methodology}

Six MAPS stations were operated in 2011, three in natural conditions (MUSR, BPND, VWET), two in reclaimed overburden and sand dump areas (GWAY, BISN), and one at the revegetated edge of a small reservoir (BCDS). Nets within each station were distributed in an approximate ratio of 2:1 in riparian habitat versus nearby forest habitats. For this pilot program, the emphasis on shrubby riparian edge habitat near tall upland forest was a deliberate approach to focus effort on habitats in which mist-netting is most effective, and to reduce habitat variability among sites. GWAY is located in a Provincially-certified reclaimed area; BISN is reclaimed but not certified. Stations were selected after review of data from impact assessment and monitoring programs conducted at or near these stations from 2003 to present, an evaluation of the suitability of each site for mist-netting, and accessibility. 
Each MAPS station was established and operated in accordance with the standardised protocol established by the IBP (DeSante et al., 2011). The number of net lanes at each site varied from eight to 13, on the basis of habitat configuration and the ability to operate the station without compromising bird safety. On each day of operation, one $12 \mathrm{~m}$ long, $30 \mathrm{~mm}$ mesh, 4-tier nylon mist-net was erected in each net lane, and opened for six hours beginning at local sunrise. Each mist-net samples birds breeding within an area of approximately $100 \mathrm{~m}$ radius from the net (DeSante et al., 2011).

Captured birds were identified to species, age, and sex, and a numbered aluminium leg band was applied to the right leg. The Canadian Wildlife Service National Wildlife Research Centre's Bird Banding Office and the United States Geological Survey's Bird Banding Laboratory supply the bands. These agencies jointly administer North American bird banding programs, and track all bands issued. The number of individual adult birds captured per 600 net-hours is a standard unit used as an index of adult population size in the MAPS and other bird-banding programs (Peach et al., 1996; DeSante et al., 2011). Post-fledging productivity was estimated by dividing the number of young (hatch-year; HY) by the number of adults (after hatch-year; AHY). The behaviour (e.g. nesting, feeding of young, territoriality) of each bird species observed during the operation of a station was also noted, using the procedure defined within the MAPS protocol (DeSante et al., 2011). These observations are used to categorise each species as a breeder, usual breeder, or likely breeder in the habitats encompassed within a station.

The habitat at each station was characterised using the Habitat Structure Assessment procedures established by the IBP (Nott et al., 2003). This provides a quantitative means of comparing habitats among MAPS stations.

\section{Data}

The numbers of birds newly banded, released unbanded, and recaptured are presented in Table 1. A total of 1,937 captures of 51 species occurred at the six stations during the summer of 2011. Capture rate was highest at MUSR (885 birds per 600 net-hr), and lowest at GWAY (140). The average capture rate for natural stations (BPND, MUSR, VWET) was 587 birds per 600 net-hours; capture rate at the reclaimed BISN station ( 730 birds per 600 net-hr) exceeded the natural habitat rate. Average capture rate across all stations (mean 553 birds per 600 net-hr) greatly exceeded the 189 birds per 600 net-hours recorded during the 1992 to 2006 period in the Boreal \& Arctic Canada Region of the MAPS program (Figure 1; IBP, unpublished data). Capture rates also exceeded all other six-station MAPS programs in the entire MAPS network; previously the highest capture rates were at the Yosemite National Park MAPS location, where about 400 birds per 600 net-hours are captured each year.

Table 1 Banding data from MAPS stations in the boreal forest in the oil sands region (2011)

\begin{tabular}{lccccccc}
\hline Station & New & Unbanded & Recaptures & Total & Net-hours & Capture Rate & $\begin{array}{c}\text { Species } \\
\text { (Listed*) }\end{array}$ \\
\hline BCDS & 400 & 16 & 70 & 486 & 362 & 806 & $34(4)$ \\
BISN & 362 & 2 & 55 & 419 & 344 & 730 & $37(4)$ \\
GWAY & 64 & 2 & 30 & 96 & 411 & 140 & $19(1)$ \\
BPND & 205 & 6 & 58 & 269 & 362 & 445 & $29(4)$ \\
MUSR & 375 & 6 & 48 & 429 & 291 & 885 & $27(4)$ \\
VWET & 199 & 2 & 37 & 238 & 331 & 432 & $27(4)$ \\
Total & $\mathbf{1 , 6 0 5}$ & $\mathbf{3 4}$ & $\mathbf{2 9 8}$ & $\mathbf{1 , 9 3 7}$ & $\mathbf{2 , 1 0 1}$ & $\mathbf{5 5 3}$ & $\mathbf{5 1}(6)$ \\
\hline
\end{tabular}

* Listed as sensitive in Alberta or Canada

Diversity, measured as the number of species captured (Table 1), was highest at BISN (37 species), and lowest at GWAY (19). Early successional species (e.g. sparrows) were present in greater numbers at BISN, 
consistent with its early post-reclamation successional state. Adult population size for all species pooled (Table 2) was highest at BCDS (464.5 AHY per 600 net-hr) and lowest at GWAY (111.1). The ratio of young (HY) birds to adults (AHY) resulted in reproductive indices (of post-fledging productivity) that were highest for BISN (1.28), and lowest for GWAY (0.24).

Table 2 Adult population size and productivity at boreal forest MAPS stations in the oil sands region (2011)

\begin{tabular}{llccc}
\hline Station & $\begin{array}{c}\text { Hatch-Year } \\
(\mathbf{H Y})^{*}\end{array}$ & $\begin{array}{c}\text { After Hatch-Year } \\
(\text { AHY)* }\end{array}$ & HY:AHY \\
\hline BCDS & 335.1 & 464.5 & 0.72 \\
BISN & 409.5 & 318.9 & 1.28 \\
GWAY & 26.3 & 111.1 & 0.24 \\
BPND & 135.7 & 306.2 & 0.44 \\
MUSR & 451.9 & 425.0 & 1.06 \\
VWET & 237.7 & 192.3 & 1.24 \\
Average & $\mathbf{2 6 6 . 0}$ & $\mathbf{3 0 3 . 0}$ & $\mathbf{0 . 8 8}$ \\
\hline
\end{tabular}

* Individuals per 600 net-hours (IBP standard units)

Breeding status observations provide additional insight into the quality of bird habitat, and data in support of that collected in the banding component of the program. Several species that were not captured and banded were observed exhibiting breeding behaviours (nesting, feeding of young, territoriality) in the station habitats. The number of species demonstrating breeding behaviour (Table 3) within two of the three natural habitat stations (36 and 28 at BPND and MUSR, respectively) was higher than those observed at GWAY and BISN (23 and 19, respectively), although the number of species exhibiting breeding behaviours at the other natural station (VWET) was similar to that observed in the two reclaimed areas. At BCDS, 32 species were observed exhibiting breeding behaviours; habitats at BCDS appear to support nesting, reproduction and diversity at levels similar to those in natural areas. Between five and nine species observed at each of the MAPS stations are listed as sensitive species in Alberta or Canada and between two and four listed species were judged to be breeding within the habitats at each station (Table 4).

Table 3 Avian diversity at 2011 MAPS Stations in the oil sands region

\begin{tabular}{lcccc}
\hline & \multicolumn{2}{c}{ Species Observed } & \multicolumn{2}{c}{ Breeders* } \\
Station & Total & Listed & Total & Listed \\
\hline BCDS & 52 & 9 & 32 & 4 \\
BISN & 47 & 7 & 19 & 4 \\
GWAY & 43 & 6 & 23 & 2 \\
BPND & 54 & 7 & 36 & 3 \\
MUSR & 47 & 8 & 28 & 4 \\
VWET & 40 & 5 & 21 & 2 \\
\hline
\end{tabular}

* Likely and confirmed breeding species, per DeSante et al. (2011) 
Table 4 Species identified in Canadian and Provincial sensitive species lists exhibiting breeding behaviours at boreal forest MAPS stations in the oil sands region (2011)

\begin{tabular}{lcccccc}
\hline Species & BCDS & BISN & GWAY & BPND & MUSR & VWET \\
\hline $\begin{array}{l}\text { Sharp-tailed Grouse Tympanuchus } \\
\text { phasianellus }\end{array}$ & & $\mathrm{X}$ & & & & \\
$\begin{array}{l}\text { Black Tern Chlidonias niger } \\
\text { Least Flycatcher Empidonax minimus }\end{array}$ & $\mathrm{X}$ & $\mathrm{X}$ & $\mathrm{X}$ & $\mathrm{X}$ & $\mathrm{X}$ & $\mathrm{X}$ \\
Common Yellowthroat Geothlypis trichas & $\mathrm{X}$ & $\mathrm{X}$ & $\mathrm{X}$ & $\mathrm{X}$ & & $\mathrm{X}$ \\
Cape May Warbler Setophaga tigrina & & $\mathrm{X}$ & & $\mathrm{X}$ & $\mathrm{X}$ & \\
Canada Warbler Cardellina canadensis & & & & & $\mathrm{X}$ & \\
Western Tanager Piranga ludoviciana & & & & & $\mathrm{X}$ & \\
\hline
\end{tabular}

The estimated cover and number of plant species present in each vertical vegetation layer in each major habitat type present at each station are presented in Table 5. Boreal forest vegetation diversity is apparent in these data, which was reduced for the pilot MAPS program by establishment of stations primarily within riparian habitats. At GWAY, midstory cover is low (20\%) in the mixedwood forest habitat, which covers $65 \%$ of the area. The same absence of midstory within the mixedwood forest at BISN is apparent, however, the area coverage of this habitat type is much lower $(10 \%)$. Reduced midstory and understory coverage is also apparent within the conifer forest habitat at MUSR; however, this habitat covers only $20 \%$ of the station.

\section{$4 \quad$ Results}

Receipt of reclamation certification in Alberta depends on demonstration that a reclaimed area has achieved a minimum level of ecological function and diversity. Recent reviews of environmental issues and concerns associated with the oil sands industry (The Royal Society of Canada Expert Panel, 2010; Alberta Environmental Monitoring Panel, 2011; Oil Sands Advisory Panel, 2010, 2011; Government of Canada and Government of Alberta, 2012) emphasise the need to maintain biodiversity. Habitat management to enhance reproductive success on the breeding grounds is one management option available to maintain sustainable populations (Nott, 2008), an approach that can be incorporated into reclamation planning and execution (Nott et al., 2005).

Avian monitoring using inventory, point count, census and area-search techniques provide data supportive of presence/absence determinations, relative abundance of individual species, calculation of species richness and other diversity indices. Over time, these indices can also be used to track population trends and shifts in avian community composition (Cumming et al., 2010). However, the underlying processes driving population change over time and in response to human disturbance cannot be determined using these methods. Data providing an understanding of the demographic components of species occupying these areas are required to determine if the habitat being evaluated is functional, supporting the reproductive success of a species, or if it is a sink area within which productivity rate falls short of counterbalancing the adult mortality rate. While mist-netting has inherent limitations, particularly in tall forest habitats in which nets may not be effectively hidden and which birds may not encounter as they forage in the upper canopy (Remsen and Good, 1996), this method is one of the few that can provide demographic data, an approach successfully applied in the continental MAPS program. Providing that the limitations are understood, appropriate statistical approaches may be applied and conclusions drawn.

The first of the two long-term objectives of the MAPS program in the oil sands region is to evaluate the effectiveness of reclaimed habitats for supporting avian productivity, survivorship, and diversity. The two reclaimed habitats, GWAY and BISN, performed differently as evidenced by the population metrics (Tables 1 and 2), and diversity and breeding status observations (Tables 1 and 3). The values for capture rate, adult population size (AHY) and productivity (HY:AHY) at GWAY were lower than those for the natural 
habitats, while the values for these metrics at BISN were approximately equal to or greater than those at the natural stations (BPND, MUSR, VWET) and the reservoir shoreline station (BCDS).

Table 5 Habitat Structure Assessment of the boreal forest MAPS stations in the oil sands region (2011)

\begin{tabular}{|c|c|c|c|c|c|c|c|c|c|c|}
\hline \multirow[b]{2}{*}{ Station } & \multirow[b]{2}{*}{$\begin{array}{l}\text { Primary } \\
\text { Vegetation Types }\end{array}$} & \multirow{2}{*}{$\begin{array}{c}\% \text { of } \\
\text { Station } \\
\text { Area }\end{array}$} & \multicolumn{2}{|c|}{$\begin{array}{l}\text { Upperstory } \\
\text { (>15 m) }\end{array}$} & \multicolumn{2}{|c|}{$\begin{array}{l}\text { Midstory } \\
\text { (5-15 m) }\end{array}$} & \multicolumn{2}{|c|}{$\begin{array}{l}\text { Understory } \\
(0.5-5 \mathrm{~m})\end{array}$} & \multicolumn{2}{|c|}{$\begin{array}{l}\text { Ground } \\
\text { Cover } \\
(<0.5 \mathrm{~m})\end{array}$} \\
\hline & & & $\begin{array}{l}\text { Cover } \\
(\%)\end{array}$ & $\begin{array}{l}\text { No. } \\
\text { Spp. }\end{array}$ & $\begin{array}{l}\text { Cover } \\
(\%)\end{array}$ & $\begin{array}{l}\text { No. } \\
\text { Spp. }\end{array}$ & $\begin{array}{l}\text { Cover } \\
(\%)\end{array}$ & $\begin{array}{l}\text { No. } \\
\text { Spp. }\end{array}$ & $\begin{array}{l}\text { Cover } \\
(\%)\end{array}$ & $\begin{array}{l}\text { No. } \\
\text { Spp. }\end{array}$ \\
\hline \multirow[t]{3}{*}{ BCDS } & Willow & 45 & - & - & 20 & 4 & 90 & 10 & 85 & $>25$ \\
\hline & Aspen & 40 & 95 & 1 & 10 & 5 & 70 & 10 & 90 & $>25$ \\
\hline & Diversion Channel & 15 & - & - & 5 & 2 & 80 & 10 & 70 & 10 \\
\hline \multirow[t]{3}{*}{ BISN } & Willow-Aspen & 70 & - & - & - & - & 90 & 10 & 90 & 10 \\
\hline & Conifer & 20 & 5 & 2 & 95 & 4 & 5 & 5 & 10 & 10 \\
\hline & Mixedwood & 10 & - & - & 5 & 1 & 80 & 10 & 90 & 10 \\
\hline \multirow[t]{4}{*}{ GWAY } & Mixedwood & 65 & 50 & 3 & 50 & 4 & 20 & 10 & 70 & 15 \\
\hline & Marsh & 20 & - & - & 10 & 2 & 80 & 25 & 90 & $>25$ \\
\hline & Aspen-Willow & 10 & - & - & 10 & 4 & 90 & 15 & 95 & $>25$ \\
\hline & Grassland & 5 & - & - & 10 & 4 & 70 & 10 & 65 & 10 \\
\hline \multirow[t]{3}{*}{ BPND } & Conifer & 65 & 10 & 2 & 40 & 4 & 90 & 15 & 95 & $>25$ \\
\hline & Willow-Aspen & 25 & - & - & 20 & 5 & 40 & 25 & 35 & $>25$ \\
\hline & Aspen & 10 & 80 & 2 & 10 & 2 & 70 & 10 & 95 & $>25$ \\
\hline \multirow[t]{3}{*}{ MUSR } & Mixedwood & 60 & 60 & 2 & 10 & 2 & 50 & 15 & 90 & $>25$ \\
\hline & Conifer & 20 & 80 & 1 & 10 & 1 & 5 & 1 & 70 & 10 \\
\hline & Willow & 20 & - & - & 5 & 1 & 95 & 15 & 75 & $>25$ \\
\hline \multirow[t]{3}{*}{ VWET } & Aspen & 65 & 90 & 2 & 10 & 3 & 90 & 15 & 90 & $>25$ \\
\hline & Willow & 20 & 10 & 1 & 10 & 3 & 80 & 15 & 90 & $>25$ \\
\hline & Sedge & 15 & - & - & - & - & 90 & 3 & 80 & 15 \\
\hline
\end{tabular}

The habitats in which GWAY and BISN are situated are reclaimed overburden dumps. Soil placement occurred in the late 1970s at GWAY, and revegetation was complete in 1983. At BISN, soil placement was completed in the early 1990 s, with revegetation being mostly complete by 1992 . A subsequent planting (spruce) in the grassland habitat (Table 5) occurred in the early 2000s and these trees are now approaching $3 \mathrm{~m}$. The difference between the GWAY and BISN habitats may reflect the 20 year age difference between the areas, and improvements in reclamation practices applied at BISN relative to those applied earlier at GWAY, including the depth of coversoil placement and the direct placement at BISN of coversoil obtained from nearby mining operations. High capture numbers of young birds at BISN during pre-migration flocking may reflect the connectivity of BISN habitats to nearby natural areas, independent of habitat reconstruction effects, and as reclamation around GWAY progresses and connectivity is re-established, avian populations and diversity may return to levels approximating those in natural environments. 
At GWAY, lower populations, productivity and diversity may be attributed to the absence of complex vegetative patterns, particularly vertically (Table 5). Within conifer, aspen and mixedwood forest patches in and around the net array at GWAY, ground, short shrub and tall shrub species cover is less dense and complex than at the natural (and BCDS) stations; these layers are important for cover and food production necessary to support higher bird populations and productivity. However, other habitat characteristics, such as patch size and pest management practices may be contributing to the lower GWAY bird capture rate. A comprehensive vegetation assessment, including ecosite phase interpretation (Beckingham and Archibald, 1996), will be completed at these stations in 2012.

The second of the two objectives of the MAPS program in the oil sands region is to provide estimates of population vital rates for bird species nesting in the boreal forest. Productivity has been calculated for most species captured in 2011; however, the high variability in the boreal forest coupled with high inter-annual variability in climate and other factors affecting breeding birds requires that several years of data be obtained in order to derive meaningful productivity rates. Whereas population size and productivity can be assessed from MAPS data on an annual basis, derivation of population trends and survivorship estimates (using Modified Cormack-Jolly-Seber mark-recapture analyses) requires a minimum of three years of data collection (Pollock et al., 1990; Lebreton et al., 1992), with six or more years sometimes required to obtain adequate precision. Both of these metrics require minimum adult bird capture rates and these can be combined and/or compared with those from the North American-wide MAPS program.

The 1,937 landbird captures from the six stations in the oil sands region substantially increases the total MAPS data from the Boreal and Arctic Canada Region (Figure 1), representing nearly one-third of that collected in the entire region from 1992 to 2006 (IBP, unpublished data). Extension of the MAPS program into the oil sands region has the potential to substantially increase the knowledge base for boreal forest bird populations. Captures for nine species at the six stations were higher in 2011 than the total from 15 years throughout the rest of the region, for nine additional species more than half the 15 year capture total was achieved in one year, and for an additional eight species at least 10 captures were recorded. Overall, this would result in over 25 target species for detailed population trend and survival analyses when at least three years of data become available. Although few species identified as being sensitive in Alberta or Canada were captured in 2011 (Table 4), the placement of additional stations at locations where these species may be captured could provide data of particular value in the evaluation of population trends and management of reclaimed habitats for these species.

\section{Conclusions}

The first year of the MAPS program in the oil sands region clearly demonstrated the applicability of the MAPS protocol in the boreal forest, and the utility of the program in evaluating habitat quality in reclaimed areas. Firm conclusions regarding reclaimed habitat performance require a minimum of two more years of data collection. However, improvements in reclamation practices at BISN relative to those applied earlier at GWAY are suggested in the MAPS banding and breeding status observation data from 2011. Avian data collected using the MAPS protocol may be used in planning future reclamation programs and in support of applications for reclamation certification, and will contribute to meeting project-specific approval conditions.

Eighteen additional stations will be established and operated in 2012, and will include stations in reclaimed oil sands areas of differing ages, near oil sands industrial operations, and in habitats affected by other (e.g. urban) developments and human activities. These 18 stations will be established in riparian habitats near forest systems similar to those established in 2011. To ensure that an understanding of the performance of natural habitats, and natural variability, is acquired and available for the assessment of performance of reclaimed and affected habitats, a 1:1 ratio of reclaimed/affected stations to natural stations will be maintained. The set of 24 stations is intended to provide data on which variability in avian population dynamics can be understood, within a defined natural habitat (riparian-based) as compared to reclaimed habitats. Further expansion of the program in future years will include consideration of other major boreal forest habitats, such as bogs and fens. 
Regional application of the MAPS protocol will contribute to the understanding of large-scale development impacts on bird populations. These data will be supplied to the North American-wide database maintained by the IBP and will support population trend analyses. Construction and management of reclaimed habitats to enhance reproductive success on the breeding grounds in the boreal forest is an approach that may have the potential to maintain sustainable bird populations near industrial developments.

\section{Acknowledgement}

Mr Fred Payne (Syncrude Canada Ltd) and Mr Scott Rose (Hammerstone Corporation) invested a substantive effort within their organisations that resulted in significant corporate support from both organisations, which is gratefully acknowledged. Mr Doug Collister, Dr Marcel Gahbauer, Mr Rainer Ebel provided scientific oversight and support. The substantive efforts of Ms Danielle Kaschube, Mr Ron Taylor, Dr Rodney Siegel, and Dr David DeSante of the Institute for Bird Populations are acknowledged with gratitude. Ms Jane Elser and Ms Christine Sparling provided volunteer assistance on a number of early mornings, and we are very grateful for their help. This is contribution number 444 of the Institute for Bird Populations.

\section{References}

Alberta Environmental Monitoring Panel (2011) A World Class Monitoring, Evaluation and Reporting for Alberta, The Report of the Alberta Environmental Monitoring Panel, 102 p., viewed 13 May 2012, http://environment.gov.ab.ca/info/library/8381.pdf.

Alberta Sustainable Resource Development (2010) General Status of Wild Species 2010, viewed 13 May 2012, http://srd.alberta.ca/FishWildlife/SpeciesAtRisk/GeneralStatusOfAlbertaWildSpecies/GeneralStatusofAlbertaWildSpecies20 10/Default.aspx.

Beckingham, J.D. and Archibald, J.H. (1996) Field guide to ecosites of northern Alberta. Natural Resources Canada, Canadian Forest Service, Northwest Region, Northern Forest Centre, Special Report 5, Edmonton, Alberta, 528 p.

Blancher, P. and Wells, J. (2005) The Boreal Forest Region: North America's Bird Nursery, The Boreal Songbird Initiative and the Canadian Boreal Initiative, Bird Studies Canada, viewed 13 May 2012, http://www.bsc-eoc.org/borealnurseryrpt.html.

Committee on the Status of Endangered Wildlife in Canada (2011), Government of Canada, viewed 13 May 2012, http://www.cosewic.gc.ca/eng/sct0/rpt/dsp_booklet_e.htm.

Crewe, T.L., McCracken, J.D., Taylor, P.D., Lepage, D. and Heagy, A. (2008) Ten-Year Report on Monitoring Landbird Population Change, Bird Studies Canada, The Canadian Migration Monitoring Network and Environment Canada, 71 p., viewed 13 May 2012, http://www.bsc-eoc.org/download/CMMNReport2008.pdf.

Cumming, S., Schmiegelow, F., Bayne, E. and Song, S. (2010) Canada's Forest Resource Inventories: Compiling a Tool for Boreal Ecosystems Analysis and Modelling. A Background Document, 7 p., viewed 13 May 2012, http://www.borealbirds.ca/files/technical_reports/CAS_Backgrounder_v1.0.pdf.

DeSante, D.F. (1995) Suggestions for future directions for studies of marked migratory landbirds from the perspective of a practitioner in population management and conservation, Journal of Applied Statistics, Taylor \& Francis Group, 22, pp. 949965.

DeSante, D.F. and Rosenberg, D.K. (1998) What do we need to monitor in order to manage landbirds? Avian Conservation: Research Needs and Effective Implementation, Marzluff, J and Sallabanks, R (eds.), Island Press, Washington, DC, pp. 93106.

DeSante, D.F., O'Grady, D.R. and Pyle, P. (1999) Measures of productivity and survival derived from standardized mist netting are consistent with observed population changes, Bird Study, Taylor \& Francis Group, 46 (suppl.) pp. 178-188.

DeSante, D.F., Nott, M.P. and O'Grady, D.R. (2001) Identifying the proximate demographic cause(s) of population change by modeling spatial variation in productivity, survivorship, and population trends, Ardea, Netherlands Ornithologist's Union, 89, pp. $185-207$.

DeSante, D.F. and Saracco, J.F. (2009) Power of the MAPS program to detect differences and trends in survival and a vision for program expansion, Bird Populations, Institute for Bird Populations, 9, pp. 42-75.

DeSante, D.F., Burton, K.M., Velez, P. and Froehlich, D. (2011) 2011 MAPS Manual, The Institute for Bird Populations, 49 p.

Government of Canada and Government of Alberta (2012) Joint Canada/Alberta Implementation Plan for Oil Sands Monitoring, Environment Canada, 32 pp., viewed 13 May 2012, http://www.ec.gc.ca/pollution/EACB8951-1ED0-4CBB-A6C984EE3467B211/Final\%200S\%20Plan.pdf.

Government of Canada (2009) Species at Risk Act, Environment Canada, viewed 13 May 2012, http://www.sararegistry.gc.ca/species/schedules_e.cfm?id=1.

Lebreton, J.D., Burnham, K.P., Clobert, J. and Anderson, D.R. (1992) Modeling survival and testing biological hypotheses using marked animals: a unified approach with case studies, Ecological Monographs, Ecological Society of America, 62, pp. 67118.

Nott, M.P., DeSante, D.F. and Michel, N. (2003) Monitoring Avian Productivity and Survivorship (MAPS) Habitat Structure Assessment Protocol, The Institute for Bird Populations, $48 \mathrm{p}$. 
Nott, P., Michel, N., Pyle, P. and DeSante, D.F. (2005) Managing Landbird Populations in Forests of the Pacific Northwest Region, Institute for Bird Populations, 7 p., viewed 13 May 2012, http://www.birdpop.org/usfsr6/downloads/NWFExecReport.pdf.

Nott, P. (2008) Demographic Landbird Monitoring: A Precision Tool for Land Stewards, The Institute for Bird Populations, 4 p., viewed 13 May 2012, http://www.birdpop.org/downloaddocuments/demographic_justification.pdf.

Oil Sands Advisory Panel (2010) A Foundation for the Future: Building an Environmental Monitoring System for the Oil Sands, A Report Submitted to the Minister of the Environment, Environment Canada, 49 p., viewed 13 May 2012, http://www.ec.gc.ca/pollution/default.asp?lang=En\&n=E9ABC93B-1.

Oil Sands Advisory Panel (2011) An Integrated Oil Sands Environment Monitoring Plan, Environment Canada, 31 pp., viewed 13 May 2012, http://www.ec.gc.ca/default.asp?lang=En\&n=56D4043B-1\&news=7AC1E7E2-81E0-43A7-BE2B-4D3833FD97CE.

Peach, W.J., Buckland, S.T. and Baillie, S.R. (1996) The use of constant effort mist-netting to measure between-year changes in the abundance and productivity of common passerines, Bird Study, Taylor \& Francis Group, 43, pp. 142-156.

Pollock, K.H., Nichols, J.D., Brownie, C. and Hines, J.E. (1990) Statistical inference for capture-recapture experiments, Wildlife Monographs, Wiley, 107, pp. 1-97.

Remsen, J.V. and Good, D.A. (1996) Misuse of data from mist-net captures to assess relative abundance in bird populations, The Auk, The American Ornithologists' Union, 113, pp 381-398.

The Royal Society of Canada Expert Panel (2010) Environmental and Health Impacts of Canada's Oil Sands Industry, The Royal Society of Canada, The Academies of Arts, Humanities and Sciences of Canada, 441 p., viewed 13 May 2012, http://www.rsc.ca/documents/expert/RSC\%20report\%20complete\%20secured\%209Mb.pdf.

Savage, C. (2004) The Singing Forest. Canadian Geographic, Royal Canadian Geographic Society, 124, pp. 36-46.

Saracco, J.F., DeSante, D.F, Nott, M.P. and Kaschube, D.R. (2009) Using the MAPS and MoSI Programs to Monitor Landbirds and Inform Conservation, Proceedings of the Fourth International Partners in Flight Conference: Tundra to Tropics, Rich, T.D., Thompson, C.D, Demarest, D. and Arizmendi, C. (eds), University of Texas-Pan American Press, Edinburg, TX, pp. 651-658.

Wells, J.V. (2011) Boreal birds of North America: A Hemispheric View of their Conservation Links and Significance, University of California Press, Berkeley, CA, 136 p. 
